\title{
Efficiency Measurements of Ultrasonic Generator for Welding
}

\author{
W. KARDYŚ* AND A. MiLEWSKI \\ Tele and Radio Research Institute, Ratuszowa 11, 03-450 Warsaw, Poland \\ (Received March 18, 2015)
}

\begin{abstract}
The paper presents results of theoretical analysis as well as practical measurements of efficiency in ultrasonic welding system with main focus on ultrasonic generator. Through analysis and tests were performed using $3 \mathrm{~kW}$ $20 \mathrm{kHz}$ Sonic Blaster ultrasonic generator manufactured by ITR. Special equipment was used to perform accurate measurements of input and output power of such generator since an output signal of the ultrasonic generator has high voltage amplitude up to $3 \mathrm{kV}$ and frequency of $20 \mathrm{kHz}$. Artificial load able to dissipate up to $6 \mathrm{~kW}$ of continuous power was designed to simulate ultrasonic transducer. Power measurements were performed on the mains supply of the generator using accurate true RMS power meter and load side measurements were performed using specially built power metering system able to measure high voltage $20 \mathrm{kHz}$ signals based on calibrated high voltage resistive divider and high frequency current transducer.
\end{abstract}

DOI: 10.12693 /APhysPolA.128.456

PACS: 81.20.Vj, 43.35.-c, 43.35.+d, 77.65.Dq, 77.84.Cg, 85.50.-n

\section{Introduction}

An ultrasonic generator is a part of a welding machine responsible for powering an ultrasonic stack. It generates sinusoidal wave of precisely regulated frequency with typical resolution up to $0.1 \mathrm{~Hz}$. Frequency range and output power of such device depends on required welding parameters. Typical systems operate in a narrow frequency range around base frequency which depends on construction of ultrasonic stack. The base frequency is usually selected from $20 \mathrm{kHz}$ to $40 \mathrm{kHz}$. Output power varies from over a dozen $\mathrm{W}$ up to a few $\mathrm{kW}[1]$.

Presented article focuses on $20 \mathrm{kHz}$ ultrasonic generator Sonic Blaster 20/3 designed and manufactured by Tele and Radio Research Institute. Maximum output power of this generator is $3 \mathrm{~kW}$. It is based on a resonant converter topology with digital control and measurements. More information about this design can be found in [1-3].

Ultrasonic welding is often described as energy efficient technology due to the fact that energy is transformed into heat mostly in the area of a weld. This statement is true as long as losses in ultrasonic generator and stack are kept at low level. The article presents theoretical analysis and measurements of electrical efficiency of ultrasonic generator.

\section{Theoretical losses analysis}

Before conducting efficiency measurements of ultrasonic generator, theoretical analysis of electrical losses was performed. Figure 1 presents a simplified schematic of the device [4]. This schematic does not include digital control circuits, user interface, communication interfaces and other supplementary circuits integrated in the DSP

\footnotetext{
* corresponding author; e-mail: witold.kardys@itr.org.pl
}

control unit as well as transistors driver circuits and protection circuits. Those circuits were excluded from analysis because main scope of this work was to estimate efficiency of the generator power stage. Power consumption of control unit is constant and does not depend on generator's output power.

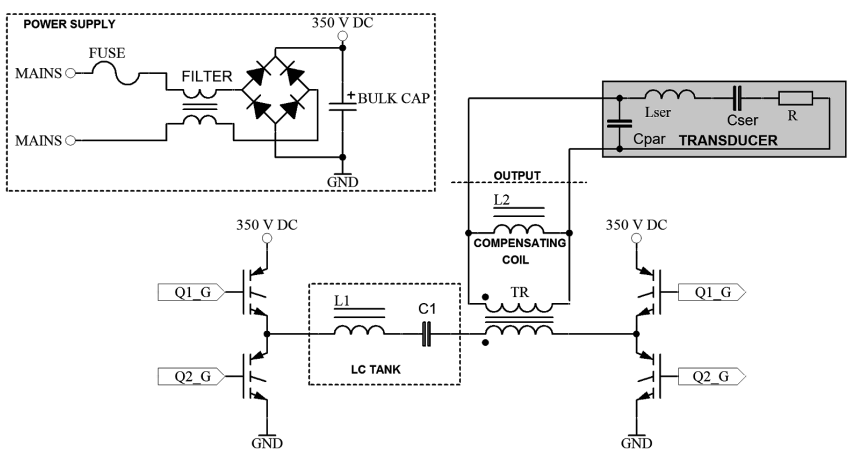

Fig. 1. Simplified schematic of ultrasonic generator.

The simplified schematic from Fig. 1 includes an ultrasonic transducer equivalent circuit. The RLC equivalent circuit used is also known as the Butterworth-Van Dyke (BVD) model. This circuit represents the load of the generator $[5,6]$.

The first step of theoretical estimation is to choose elements contributing to overall losses of the generator. Those elements were divided into 6 groups:

- power supply (rectifier, bulk capacitor),

- switching circuit (H-bridge),

- primary LC tank,

- transformer,

- secondary compensation coil,

- external capacitance and wiring. 
To calculate theoretical losses in each of the elements it is required to assume input power of the generator $P_{\text {IN }}=2.2 \mathrm{~kW}$. This value has been chosen in such a way that experimental measurements could be performed at similar power levels.

Since the efficiency is not known at this stage, all voltages and currents in the circuit were calculated using input power. This approach is reasonable due to the fact that efficiency is expected to be over $90 \%$ based on previous researches which adds insignificant error to losses estimation.

\subsection{Power supply losses — bridge rectifier}

Generator power supply consists of fuse, EMC filter, bridge rectifier and electrolytic capacitor often called bulk capacitor. Losses generated in a mains power cord and internal wiring are neglected. Fuse and filter losses are also neglected due to unknown parameters of those elements. To calculate losses in the bridge rectifier one must estimate the mains supply current according to the formula

$$
I_{\mathrm{MAINS}}=\frac{P_{\mathrm{IN}}}{U_{\mathrm{MAINS}}} .
$$

Generator is supplied from single phase mains $U_{\text {MAINS }}=$ $230 \mathrm{~V}$. Using (1) the mains current can be calculated: $I_{\text {MAINS }} \approx 9.6 \mathrm{~A}$. The bridge rectifier used in the generator is KBPC3506. According to the datasheet, the maximum instantaneous forward voltage of single diode in this bridge is $V_{\mathrm{F}}=1.1 \mathrm{~V}$. Average bridge losses can be calculate as follows:

$$
P_{\text {LOSS_BRIDGE }}=2 \times V_{\mathrm{F}} I_{\text {MAINS }} \text {. }
$$

Calculated bridge losses: $P_{\text {LOSS_BRIDGE }} \approx 21 \mathrm{~W}$.

\subsection{Power supply losses - electrolytic capacitor}

Capacitor used is PEH200 series, model 3300uF/400V. The equivalent series resistance of this capacitor is $R_{\mathrm{ESR}}=29 \mathrm{~m} \Omega$. Losses in the capacitor can be calculated according to the following formula:

$$
P_{\text {LOSS_CAP }}=\left(I_{\text {MAINS }}\right)^{2} R_{\text {ESR }} \text {. }
$$

Resulting capacitor losses $P_{\text {LOSS CAP }}=2.7 \mathrm{~W}$ are well within limits for this type of the capacitor.

\subsection{Switching circuit losses}

The switching circuit in the generator consists of 4 IGBT transistors forming an $\mathrm{H}$-bridge. The transistors type is IRGP4063D. Switching circuit losses can be divided into two categories. The first category consists of conductions losses. In IGBT transistors, those losses are effect of non-zero saturation voltage of IGBT. In used transistors this voltage has value $V_{\mathrm{CE}(\mathrm{ON})}=1.4 \mathrm{~V}$ at $10 \mathrm{~A}$ collector current. To simplify calculations it is assumed that effective transistor current is equal to the RMS supply current $I_{\text {MAINS }}$. During normal operation, all transistors in the bridge are switched with duty cycle close to $50 \%$. Conduction losses of each transistor can be calculated using the following equation:
$P_{\text {IGBT_COND }}=V_{\mathrm{CE}(\mathrm{ON})} I_{\mathrm{MAINS}} d_{\mathrm{ON}}$, where $d_{\mathrm{ON}}$ indicates a duty cycle of the transistor.

Conduction losses per transistor are $P_{\mathrm{IGBT}} \mathrm{COND} \approx$ $6.7 \mathrm{~W}$.

The second category of transistor losses are switching losses. Due to the fact that a power stage of an ultrasonic generator is designed as a resonant converter, switching losses are minimized because during switching, the transistor current is nearly zero. The only component of the switching losses are capacitance discharge losses. The output capacitance of each transistor is being discharged once each cycle when the transistor is being switched on. Switching losses are dependent on frequency of an output signal. In described case, the switching frequency is equal to $f_{\mathrm{SW}}=20 \mathrm{kHz}$ and the output capacitance of transistors used is $C_{\mathrm{OES}}=245 \mathrm{pF}$. DC voltage supplying the switching circuit is equal to $V_{\text {SUP }}{ }_{\text {DC }}=350 \mathrm{~V}$.

$$
\begin{aligned}
& E_{\mathrm{IGBT} \_\mathrm{SW}}=\frac{C_{\mathrm{OES}} V_{\mathrm{SUP} \_\mathrm{DC}}}{2}, \\
& P_{\mathrm{IGBT} \_\mathrm{SW}}=E_{\mathrm{IGBT} \_\mathrm{SW}} f_{\mathrm{SW}} .
\end{aligned}
$$

Equation (5) describes energy lost during each transistor switch-on. Equation (6) describes each transistor switching losses. Calculated values are $E_{\text {IGBT_sw }} \approx 15 \mu \mathrm{J}$ and $P_{\text {IGBT }}$ sW $\approx 0.3 \mathrm{~W}$.

Total losses of the switching circuit are described as follows:

$$
P_{\text {LOSS_SWC }}=4 P_{\mathrm{IGBT}} \text { _COND }+4 P_{\mathrm{IGBT}} \text { _sw } \text {. }
$$

Using Eq. (6) the sum of switching circuit losses can be calculated: $P_{\text {LOSS }}$ swC $\approx 28[\mathrm{~W}]$.

\subsection{Primary LC tank losses}

Primary LC tank in a resonant converter consists of a custom designed coil and polypropylene FKP1 series capacitors (high pulse current rated) LC tank losses are dominated by coil losses since dissipation factor of the FKP1 capacitors is very low. According to the datasheet, a dissipation factor is $\tan \delta<6 \times 10^{-4}$ at $10 \mathrm{kHz}$ but measurements using RLC bridge show that it is at least 10 times lower than given value at $10 \mathrm{kHz}$. Calculations of coil losses are shown in the next paragraph.

\subsection{Inductive elements losses}

The LC tank coil, transformer and the secondary compensation coil are custom designed. The LC tank coil is manufactured as a single element while the transformer and the secondary compensation coil are each split into two elements to increase power throughput of the generator. Each of those inductive elements is designed using E65/32/27 ferrite core made of 3C90 material. Losses in inductive elements can be split into two categories copper losses (conduction losses) and core losses $(B-H$ hysteresis losses).

Core losses are generally described by empirical equation, according to [7]:

$$
P_{\mathrm{m}, \mathrm{sp}}=k f^{a} B_{\mathrm{AC}}^{d}
$$

where $k, a, d$ are ferrite material and core parameters. 
Wiring losses general formula, according to [7]:

$$
P_{\mathrm{w}, \mathrm{dc}}=\rho_{\mathrm{CU}} \frac{l}{A} I_{\mathrm{RMS}},
$$

where $\rho_{\mathrm{CU}}$ - copper resistivity, $l$ - winding length, $A$ conductor cross-section area, $I_{\mathrm{RMS}}$ - effective winding current.

It is important to consider skin effect and proximity effect in calculating winding losses in inductive elements. More information about those effects and inductive elements can be found in [7].

TABLE I

Calculated losses of inductive elements.

\begin{tabular}{c|c|c|c}
\hline \hline Name of element & $\begin{array}{c}\text { Core losses } \\
{[\mathrm{W}]}\end{array}$ & $\begin{array}{c}\text { Winding } \\
\text { losses [W] }\end{array}$ & $\begin{array}{c}\text { Total element } \\
\text { losses [W] }\end{array}$ \\
\hline $\begin{array}{c}\text { primary LC } \\
\text { tank coil } \\
\text { transformers } \\
\text { secondary }\end{array}$ & 5.5 & 7 & 12.5 \\
compensation coils & $2 \times 6.3$ & $2 \times 4.3$ & $2 \times 7=14$ \\
\hline \multicolumn{3}{r|}{ Total: } & $2 \times 7.3=14.6$ \\
\hline
\end{tabular}

Inductive elements were designed using Magnetic Parts Editor tool from OrCAD 16.2 software package. This tool accurately calculates power losses in designed elements using database of ferrite cores and materials. Table I contains calculated losses of all the described inductive elements. Combined losses of all the inductive elements are $P_{\text {LOSS IND }}=41.1 \mathrm{~W}$.

\subsection{Summary of theoretical losses analysis}

Table II contains summary of theoretically calculated losses. $P_{\mathrm{LOSS}}=92.8 \mathrm{~W}$ at $P_{\mathrm{IN}}=2.2 \mathrm{~kW}$. Theoretical efficiency is $\eta=96.0 \%$.

\section{TABLE II}

Summary of theoretically calculated losses.

\begin{tabular}{c|c}
\hline \hline Element & Losses [W] \\
\hline bridge rectifier & 21 \\
bulk capacitor & 2.7 \\
IGBT transistors & 28 \\
inductive elements & 41.1 \\
Total: & 92.8
\end{tabular}

Efficiency calculations does not consider some elements:

- DSP processor control module,

- EMC filter and fuse,

- Power supply cord and internal wiring,

- Stray capacitance on PCB.

Losses in those elements will contribute to lowering generator's efficiency. On the other hand, conducted calculations assumed worst case losses. Real elements losses can be lower than calculated.
Calculations were performed assuming that the resonant converter is working near its resonant frequency, that is, the generator secondary compensation coil is well matched to the internal load capacitance (transducer parallel capacitance) which is not always the case. When the compensation is not correct switching losses in IGBT transistors rise significantly.

\section{Artificial ultrasonic load}

To accurately measure generator efficiency it is beneficial to use an artificial load instead of a real ultrasonic transducer. This approach allows multiple measurements at different load levels without danger of damaging the ultrasonic transducer. It also ensures load stability and measurements repeatability.

The artificial load of ultrasonic generator differs greatly from a standard artificial electronic dc or ac load. First of all, the ultrasonic artificial load has to operate at relatively high frequency in a range from $20 \mathrm{kHz}$ up to at least $40 \mathrm{kHz}$. The second inconvenience is the voltage range of the generator's output signal. For the $3 \mathrm{~kW}$ version the output voltage can be as high as $2 \mathrm{kV}$ RMS. Lastly, ultrasonic transducer has a significant parallel capacitance which is compensated using a specially designed coil built into the generator. The artificial load must contain a parallel capacitance equal to the transducer's capacitance to allow proper operation of generator's output stage and thus proper energy transfer to the load. Since there is no commercially available ultrasonic artificial load, such a device had to be designed and manufactured.

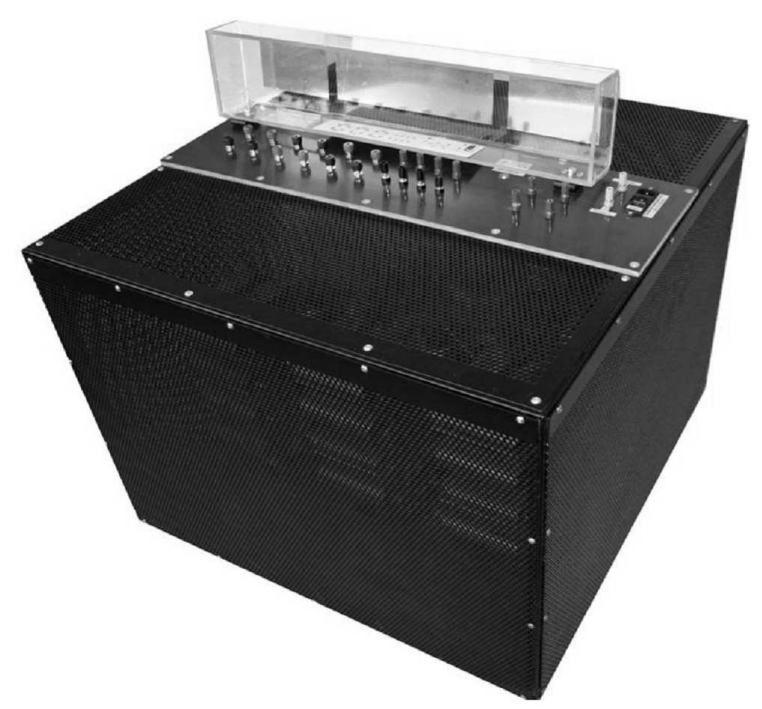

Fig. 2. Ultrasonic artificial load.

Figure 2 presents the manufactured artificial load unit. It consists of 6 sections of low inductance, high power resistors mounted on isolated radiators equipped with fans and 2 sections of capacitors. Each section of resistors 


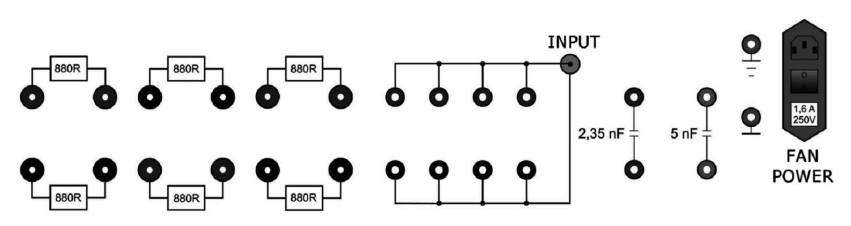

Fig. 3. Connection plate of ultrasonic artificial load.

has resistance of $880 \Omega$ and is capable of constantly dissipating up to $1 \mathrm{~kW}$ of electrical power and withstanding voltages up to $3 \mathrm{kV}$ RMS. Combined resistive sections can dissipate up to $6 \mathrm{~kW}$ of constant electrical power. Capacitive sections have two different capacities of $5 \mathrm{nF}$ and $2.35 \mathrm{nF}$ and can withstand voltages up to $5 \mathrm{kV}$ peak (3.5 kV RMS). All resistive and capacitive sections are isolated from each other and from case and are connected to banana sockets mounted on an isolated plate equipped with a special cover. This plate is also equipped with a high voltage connector which allows connection of an ultrasonic generator using a high voltage cable. The connector plate is used to change impedance of the artificial load by connecting the available sections in different configurations. Figure 3 presents a connector plate schematic. The whole device is enclosed in a grounded metal case with ventilation holes and wheels which allows transportation as the device has large dimensions and mass in excess of $80 \mathrm{~kg}$.

\section{Measurements}

Measurement setup consisted of GSB 20/3 ultrasonic generator, the artificial load described in the previous section and a power measurement equipment described below.

Measuring input and output power of ultrasonic generator is causing difficulties. Due to design of generator's power supply, supply current wave form is highly distorted. To accurately measure the input power in such conditions it is required to have a measurement equipment capable of calculating real power consumption instead of simply multiplying RMS current and voltage. Presented measurements were performed using MUPASZ 710 bay controller. This device is normally used as an electronic protection relay in low and medium voltage switchgears. It is able to calculate real power consumption in three phase power grid with $1 \%$ accuracy. It integrates current transducers and voltage measurement circuits and calculates harmonic content up to 40th harmonic of mains frequency using powerful DSP.

Output signal measurements are even more difficult. The output frequency is much higher than mains frequency and is equal to $20 \mathrm{kHz}$. The output voltage is $1.8 \mathrm{kV}$ RMS. No standard measurement equipment can reliably measure power in such conditions. Output power measurements were taken using setup consisting of TPS2024 isolated channel digital oscilloscope, HVP$15 \mathrm{HF}$ high voltage probe and AS-101 current transducer. HVP-15HF probe can measure voltages up to $15 \mathrm{kV}$ peak

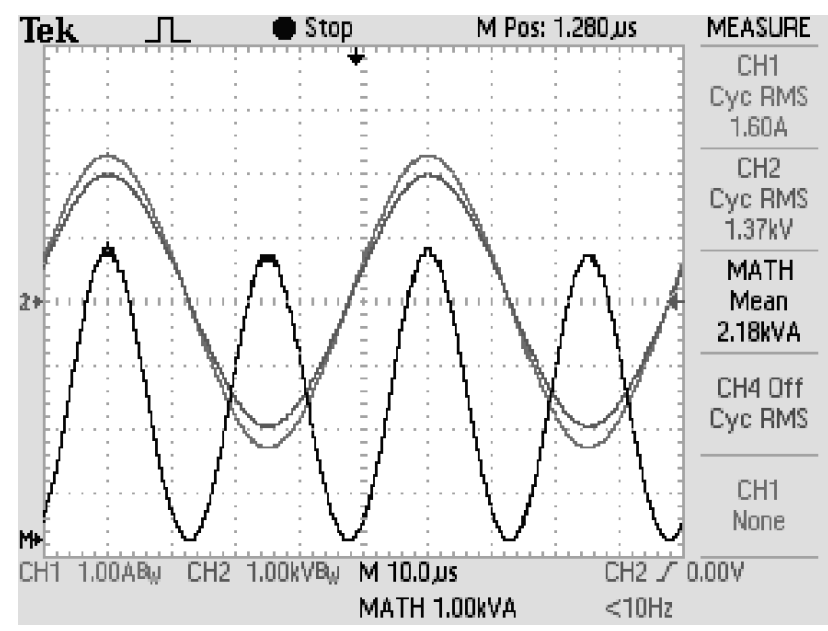

Fig. 4. Oscilloscope screen capture during output power measurements.

and has bandwidth of $50 \mathrm{MHz}$. Unfortunately, it has low accuracy of $6 \%$. To achieve an accuracy up to $0.5 \%$ this probe was calibrated using a reference probe and a function generator at $20 \mathrm{kHz}$ frequency and $10 \mathrm{~V}$ amplitude. This calibration assumes linearity of the probe in the whole voltage range since it is a passive probe. Calibration also allowed elimination of phase offset of $0.3^{\circ}$ introduced by the probe. Current transducer was calibrated in a similar way. The TPS2024 scope was used as a data acquisition unit. Figure 4 presents a screen captured from the scope during measurements. It shows the voltage and the current wave forms as well as the instantaneous power wave form created using a mathematical multiplication function built into the scope. This power wave form can be used to estimate the output power with a low accuracy because it does not include compensation and calibration data. The acquired signals data were stored in CSV format and transferred to PC. Stored data were processed in Excel 2007 on a PC to calculate real power with a phase and amplitude correction performed on raw voltage and current data.

Efficiency measurements were performed excluding the DSP control unit. This was possible due to the fact that the DSP board is powered by a separate mains power supply. Average power consumption of the DSP unit is $15 \mathrm{~W}$ including mains power supply losses.

During measurements, the artificial load was configured to resistance of $880 \Omega$. Capacitance of the load was adjusted to achieve near zero phase difference between the output voltage and current. A current transducer was connected between resistive load and generator output with parallel connected capacitance. 20 measurements were taken and averaged. Results are: input power (mains) $P_{\mathrm{IN} \text { M }}=2227 \mathrm{~W}$, output power $P_{\text {OUT }}$ m $=2131 \mathrm{~W}$, measurement accuracy $1 \%$.

Losses and efficiency calculated from measurements: $P_{\text {LOSS }}$ M $=96 \pm 44 \mathrm{~W}, \eta_{\mathrm{M}}=95.7 \pm 2 \%$.

Additional measurements were taken at different load levels. Table III presents results of all measurements. 


\section{TABLE III}

Results of efficiency measurements at different load levels.

\begin{tabular}{|c|c|c|c|c|}
\hline $\operatorname{Load}[\Omega]$ & $\mathrm{P}_{\mathrm{IN}}[\mathrm{W}]$ & $\mathrm{P}_{\text {OUt }}[\mathrm{W}]$ & $\mathrm{P}_{\text {LOSS }}[\mathrm{W}$ & Efficiency [\%] \\
\hline 2640 & 917 & 867 & 50 & 94.5 \\
\hline 1760 & 1327 & 1265 & 62 & 95.3 \\
\hline 880 & 2227 & 2131 & 96 & 95.7 \\
\hline
\end{tabular}

\section{Conclusion}

Ultrasonic generator efficiency measurement results are consistent with theoretical analysis. Accurate measurements of electrical losses are difficult because of problematic power measurements of input and output signal as well as low difference between input and output power which increases measurement uncertainty. Efficiency is fairly constant in wide load range. High efficiency is maintained provided that parallel capacitance of ultrasonic transducer is properly compensated by matched compensation coil in the generator which is not always the case.

High efficiency of ultrasonic generator supports the thesis that ultrasonic welding is energy efficient technology. Low electrical losses make it possible to decrease size and cost of the generator as well as maintain high reliability.

\section{Acknowledgments}

We gratefully acknowledge the financial support of the National Centre for Research and Development, Poland, under grant number PBS2/B9/19/2013.

\section{References}

[1] P. Kluk, Elektronika 50, 74 (2009).

[2] A. Milewski, P. Kluk, P. Kogut, Elektronika 52, 198 (2011).

[3] W. Kardyś, A. Milewski, P. Kogut, P. Kluk, Acta Phys. Pol. A 124, 456 (2013).

[4] J. Chudorliński, W. Kardyś, Elektronika 51, 99 (2010).

[5] A. Milewski, P. Kluk, W. Kardyś, P. Kogut, Postępy Akustyki, PTA, Rzeszów 2013, p. 380.

[6] W.P. Mason, Electromechanical Transducers and Wave Filters, 2nd ed., D. Van Nostrand, New York 1943.

[7] N. Mohan, T.M. Undeland, W.P. Robbins, Power Electronics, 3rd ed., Wiley, USA 2003. 